\title{
MULTI-OBJECTIVE WEATHER ROUTING OF SAILING VESSELS
}

\author{
Marcin Życzkowski \\ Rafał Szłapczyński \\ Gdańsk University of Technology, Faculty of Ocean Engineering and Ship Technology, Poland
}

\begin{abstract}
The paper presents a multi-objective deterministic method of weather routing for sailing vessels. Depending on a particular purpose of sailboat weather routing, the presented method makes it possible to customize the criteria and constraints so as to fit a particular user's needs. Apart from a typical shortest time criterion, safety and comfort can also be taken into account. Additionally, the method supports dynamic weather data: in its present version short-term, mid-term and long-term term weather forecasts are used during optimization process. In the paper the multi-objective optimization problem is first defined and analysed. Following this, the proposed method solving this problem is described in detail. The method has been implemented as an online SailAssistance application. Some representative examples solutions are presented, emphasizing the effects of applying different criteria or different values of customized parameters.
\end{abstract}

Keywords: sailing vessels, weather routing, weather forecast, comfort, penalty

\section{INTRODUCTION}

Weather routing methods for sailing vessels has long been developed due to the great regattas such as America's Cup, Cowes Races, Mug Races and others related events. For obvious reasons regatta crews are interested in accurate minimal time routes, however route optimization is a more general problem, where multiple criteria may be applied. In this paper we present a method finding a route with the shortest journey time as a main objective, while also taking into account other aspects important for route planning. Shortest journey time is obviously essential for regatta crews; however, the situation is different for other users. For example, for recreational cruises comfort throughout voyage is equally important as it largely affects the passengers' overall satisfaction. Also, the safety-associated constraints are much stronger for recreational passenger cruises. In practice this means that route planning method eliminates routes, where strong winds, and high waves can constitute serious discomfort or danger. The same concerns unexperienced sailors, who also do not need the fastest route with minimum time, but are interested in safe and comfortable sailing. On the other end of the problem, sailors looking for extreme experiences may specify maximum speed as their main objective, while lowering the level of safety restrictions.

The aim of this paper is to present a method of determining optimal sailing routes, which supports some greatly varying user requirements. All these requirements are modelled as configurable parameters of a goal function defined in the paper. Among others, this includes a newly introduced customized cost of a turn: low for experienced sailors, much higher for beginners or passenger cruises, so as to cover the inconvenience caused by a rapid change of direction. In practice applying various turn costs translates to sailing routes consisting of either multiple short tacks or just a few long ones. 
Another new element of hereby presented version of the method is that it supports dynamic weather data: all available weather forecasts are analysed simultaneously by the optimization algorithm. In the current version of the method short-term, mid-term and long-term forecasts are taken into account during route determining, though it is possible to handle practically unlimited number of forecasts.

\section{RELATED WORKS.}

The theory of sailing has been described in detail in [12]. However, the problem of deterministic route planning for a sailing vessel has not been sufficiently documented in literature. Most available publications concern routing of unmanned sailing ships $[18,19]$. Other mostly focus on weather routing of motor-driven vessels. Only a few articles since the ' 60 s to nowadays $[9,15,3,13]$ present the development of research on the route planning of sailing vessels. Discretization of vessel's motion can be found in $[23,24,11]$. Advanced deterministic route planning algorithms are presented among others in $[2,6,17]$. The basic principles of navigation are outlined in the book [8], and the use of e-navigation in [22]. A method of graph Dijkstra-based [16] weather routing for motor-driven vessels have been presented in [4]. Dynamic weather forecasts have been discussed in [14], while other dynamic data have been applied in [16]. The issue of the comfort or discomfort perceived by the crew and passengers of the boat during different journeys have been documented in [1,7]. The cost of course changes has been applied in [21], while multicriteria route optimization has been researched in $[20,5,10]$. However, in general, up till now, there has been very little published research dedicated to a deterministic weather routing of sailing vessels, and the following paper aims to fill this gap.

\section{MODEL OF THE PROBLEM}

\section{OPTIMISATION PROBLEM}

The optimisation task is to minimize a multicriteria goal function, while fulfilling all of given constraints. The assumed goal function is as follows.

$$
\begin{aligned}
& f_{g}=\sum_{i=1}^{m}\left[t_{i} \cdot c\left(\beta_{i}\right)\right]+\sum_{i=1}^{m-1}\left[t\left(\propto_{i}\right)+\right. \\
& \left.p\left(\propto_{i}\right)\right]
\end{aligned}
$$

where:

$\mathrm{m}$ - a number of straight segments (tacks) of a route, $\mathrm{i}$ - a number of a successive straight segment of a route, $t_{i}$ - a time of travelling $i$-th segment of a route $c\left(\beta_{i}\right)$ - a discomfort factor for $\mathrm{i}$-th segment of a route, resulting from a significant heel (the factor is equal to 1 for a comfortable cruise when only minor heel values occur), $t\left(\alpha_{i}\right)$ - an actual time cost of changing course, $p\left(\alpha_{i}\right)$ - an additional penalty for discomfort resulting from course changes.

The assumed optimisation constraints are as follows:

- a statically limited navigable zone (landmass, shallows and navigational obstacles)

- dynamically limited navigable zone (a vessel must avoid areas where true wind speed exceeds threshold values)

- vessel's maximal tilt should not exceed a threshold value

Below a discrete model of the abovementioned problem is developed. First, it is assumed that the considered sailing area is approximated by a grid, whose cells are navigable or not navigable, based on the sailing conditions in grid points.

\section{GRID REPRESENTATION}

The grid used here is a representation of Mercator's projection. Main elements of Mercator projection are: map scale s, initial and final latitude $\varphi_{1}, \varphi_{\mathrm{m}}$ and longitude $\lambda_{1}$, $\lambda_{\mathrm{n}}$, and the structural latitude $\varphi_{c}$, which is an arithmetic average of $\varphi_{1}$ and $\varphi_{\mathrm{m}}$.

Another element is the linear length of longitude in minutes, denoted as $l$ and given below as:

$$
l=\frac{1852000}{s} \cdot \cos \varphi_{c}[\mathrm{~mm}]
$$
by:

Next element is expanded latitude $\mathrm{V}_{\mathrm{i}}$ for $\varphi_{\mathrm{i}}$, which is given

$$
\begin{aligned}
& V_{i}=7915,70447^{\prime} \cdot \log \tan \left(45^{\circ}+\right. \\
& \left.\varphi_{i / 2}\right)-\mathrm{a} \cdot \mathrm{e}^{2} \sin \varphi_{i}-\left[\mathrm{a} \cdot \mathrm{e}^{4} / 3\right] \\
& \sin \varphi_{i}{ }^{3}
\end{aligned}
$$

where:

$\mathrm{i}=1,2 \ldots, \mathrm{m}$

$\mathrm{e}$ - is the eclipse of the Bessel earth ellipsoid

a - is the value of the semi major axis of the Bessel Earth ellipsoid expressed in minutes

Using the above we can obtain spacing between latitudes and spacing between longitude on grid determined in millimetres.

$$
\begin{aligned}
\Delta \varphi_{m m} & =\Delta \mathrm{V} \cdot \mathrm{l}[\mathrm{mm}] \\
\Delta \lambda_{m m} & =\Delta \lambda \cdot \mathrm{l}[\mathrm{mm}]
\end{aligned}
$$

Grid points $\mathrm{P}_{\mathrm{k}}$ are selected at regular intervals $\Delta \varphi$ and $\Delta \lambda . \mathrm{P}_{\mathrm{k}}$ is determined by the latitude $\varphi_{\mathrm{i}}$ and longitude $\lambda_{\mathrm{j}}$,

$$
P_{k}=\mathrm{P}_{i j}=\mathrm{P}\left(\varphi_{i}, \lambda_{\mathrm{j}}\right) \quad \mathrm{i}=1,2, . ., \mathrm{m} ; \mathrm{j}=1,2, \ldots, \mathrm{n}
$$

An example route in a grid, is shown in Fig. 1. 


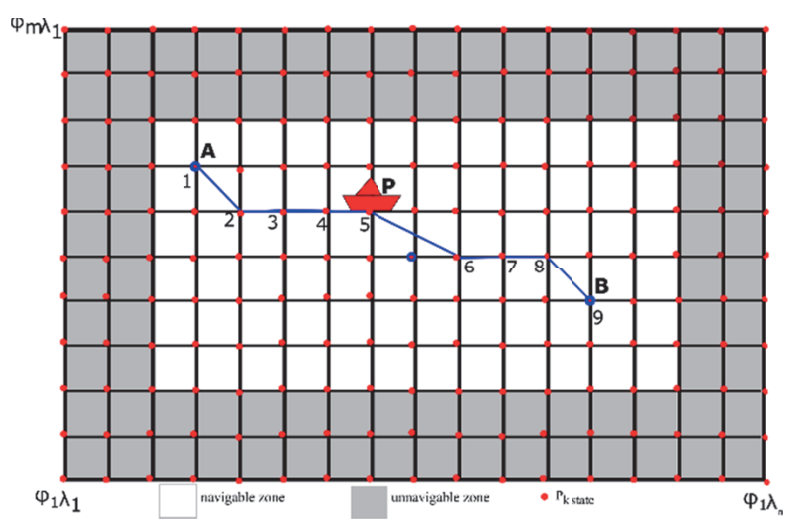

Fig. 1 The grid as navigational chart

Thus, a route can be presented as:

$$
\text { Route }=\left\{P_{1}, P_{2}, \ldots \ldots \ldots, P_{z}\right\}
$$

where:

$\mathrm{P}_{1}=\mathrm{A}$ start point of a route

$\mathrm{P}_{\mathrm{z}}=\mathrm{B}$ end point of a route

$\mathrm{z}$ - the number of points in the route

Sailing vessel movement from $\mathrm{P}_{\mathrm{k}}$ to another $\mathrm{P}_{\mathrm{k}+1}$ is determined by sailing condition $\mathrm{SC}_{\mathrm{k}}$ in point $\mathrm{P}_{\mathrm{k}}$, movement possibilities from $\mathrm{P}_{\mathrm{k}}$ to $\mathrm{P}_{\mathrm{k}+1}$ determined by the polar diagram of a specific sailing vessel.

Sailing conditions in each point $\mathrm{P}_{\mathrm{k}}$ are determined by wind vector $\vec{W}_{k}(3)$ and sea state data. In this article, only wind vector is considered:

$$
\vec{W}_{k}=\left(w_{k}, \beta_{k}\right)
$$

$\longrightarrow$ where:

$\vec{W}_{k}$ - wind vector,

$w_{k}$ - wind velocity,

$\beta_{k}$ - true wind direction.

In the proposed model, we consider 32 possible directions of movement in a grid. They are all shown in Fig. 2 .

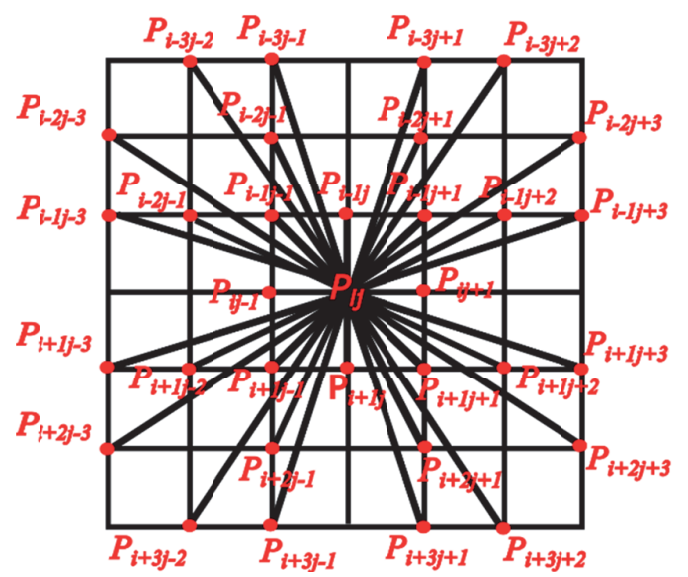

Fig. 2 Illustration of all vessel movement possibilities in a grid
A vessel's speed in each direction, depending on wind's direction and speed can be presented on a polar diagram, whose example is shown in Fig. 3.

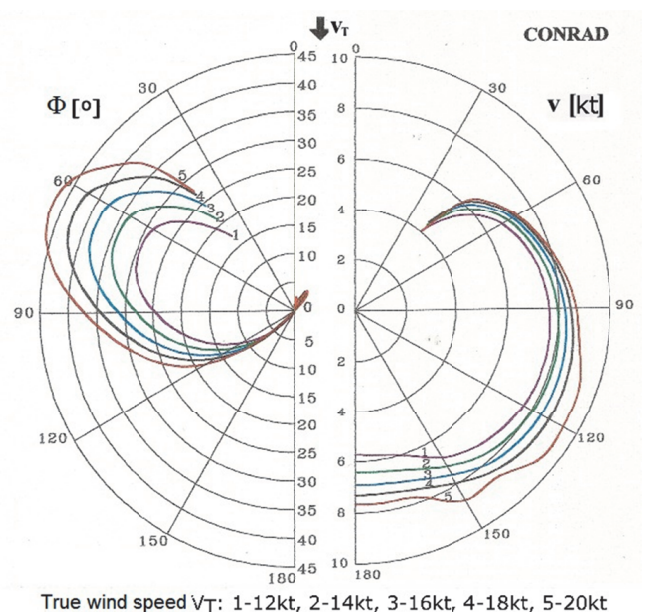

Fig. 3 Polar diagram of sailing vessel Conrad

In each point $\mathrm{P}_{\mathrm{k} \text { there }}$ is a specific wind vector. Therefore, for a particular vessel polar diagram some of the movement directions may be eliminated due to wind's direction and speed.

Each of 32 possible movements from point $\mathrm{P}_{\mathrm{k}}$ to $\mathrm{P}_{\mathrm{k}+1}$ in Fig. 2, is associated with a number parameters including a distance and vessel's velocity. A distance is calculated according to formula (7), which is used for short distances only (less than $10 \mathrm{Nm}$ ):

$$
\begin{gathered}
\operatorname{distance}\left(P_{k}, P_{k+1}\right)= \\
=\sqrt{\begin{array}{c}
\left(\varphi_{k}-\varphi_{k+1}\right)^{2}+\left(\lambda_{k}-\lambda_{k+1}\right)^{2} \\
\cdot \cos \left(\left(\varphi_{k}+\varphi_{k+1}\right) / 2\right)
\end{array}}
\end{gathered}
$$

As for velocity between points $\mathrm{P}_{\mathrm{k}}$ and $\mathrm{P}_{\mathrm{k}+1}$, formula (8) is used:

$$
\begin{aligned}
& \operatorname{velocity}\left(P_{k}, P_{k+1}\right)= \\
& =\gamma\left(\vec{W}_{k}, \alpha_{k, k+1}\right)=\gamma\left(w_{k}, \beta_{k, k+1}\right)
\end{aligned}
$$

where:

$\alpha_{k, k+1}$ - true course from $\mathrm{P}_{\mathrm{k}}$ to $\mathrm{P}_{\mathrm{k}+1}$,

$\beta_{k, k+1}$ - relative wind direction,

$\gamma\left(w_{k}, \beta_{k, k+1}\right)-\gamma$ function, computing velocity value of sailing vessel based on polar diagram for wind speed $w_{k}$ and direction $\beta_{k, k+1}$.

Next, we obtain the sailing time $t\left(P_{k}, P_{k+1}\right)$ from $\mathrm{P}_{\mathrm{k}}$ to $\mathrm{P}_{\mathrm{k}+1}$ using formula (9)

$$
\begin{aligned}
t\left(P_{k}, P_{k+1}\right)= & \operatorname{velocity}\left(P_{k}, P_{k+1}\right) \\
= & \frac{\operatorname{distance}\left(P_{k}, P_{k+1}\right)}{\sqrt{\left(w_{k}, \beta_{k, k+1}\right)}} \\
& =\frac{\sqrt{\left(\varphi_{k}-\varphi_{k+1}\right)^{2}+\left(\lambda_{k}-\lambda_{k+1}\right)^{2}}}{\cos \left(\left(\varphi_{k}+\varphi_{k+1}\right) / 2\right)}
\end{aligned}
$$


Following this, we determine the discomfort factor $c$ (from goal function (1)) for a segment between points $\mathrm{P}_{k}$ and $\mathrm{P}_{k+1}$. It is done based on the following formula (10).

$$
c\left(P_{k}, P_{k+1}\right)=1+\frac{\left(\operatorname{heel}\left(P_{k}, P_{k+1}\right)\right)^{4}}{10}
$$

The predicted heel value is dependent on the specific wind vector and the chosen move direction from $\mathrm{P}_{\mathrm{k}}$ to $\mathrm{P}_{\mathrm{k}+1}(11)$ :

$$
\begin{array}{r}
\operatorname{heel}\left(P_{k}, P_{k+1}\right)= \\
\delta\left(\vec{W}_{k}, \alpha_{k, k+1}\right)=\delta\left(w_{k}, \beta_{k, k+1}\right)
\end{array}
$$

where:

$\alpha_{k, k+1}$ - Course Over Ground from $\mathrm{P}_{\mathrm{k}}$ to $\mathrm{P}_{\mathrm{k}+1}$,

$\beta_{k, k+1}$-relative wind direction,

Function $\delta\left(w_{k}, \beta_{k, k+1}\right)$ - determines the heel of the sailing vessel based on the polar diagram for the wind speed $w_{k}$ and direction $\beta_{k, k+1}$.

True course of a vessel sailing from $\mathrm{P}_{k}$ to $\mathrm{P}_{\mathrm{k}+1}$ is presented in Fig. 4 and is determined by formula (12):

$$
\alpha_{k, k+1}=\measuredangle\left(\vec{l}, \overrightarrow{P_{k}, P_{k+1}}\right)
$$

where:

$\vec{l}$ - versor indicating north geographic, $\overrightarrow{P_{k}, P_{k+1}}$ - vector created by points $\mathrm{P}_{\mathrm{k}}$ and $\mathrm{P}_{\mathrm{k}+1}$.

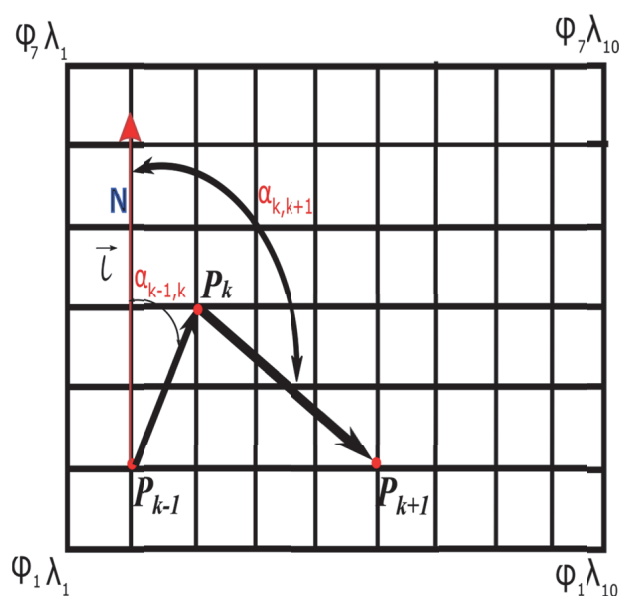

Fig. 4 Presentation of true course from $P_{k}$ to $P_{k+1}$

\section{A GRAPH-BASED SOLUTION OF THE PROBLEM}

Once a grid representation is prepared and appropriate dependencies are derived, a transformation of a grid into a graph can be performed. A graph $\mathrm{G}(\mathrm{V}, \mathrm{E})$ is created (with $\mathrm{V}$ being the set of its vertices and E being the set of its edges) as follows. Each point grid point $\mathrm{Pk}$ becomes a graph vertex and all possible movements between points in the navigable area constitute graph edges. In general, the graph takes into account multiple successive weather forecasts (three weather forecasts are used for the examples shown in this paper). As a result, the graph is a dynamic one, meaning that some of its parameters change in time due to predicted changes in the weather. The following parameters are associated with each of the graph's edges:

- $\quad \mathrm{P}_{\mathrm{k}}$ - a starting point of edge $\left(\mathrm{P}_{\mathrm{k}}, \mathrm{P}_{\mathrm{k}+1}\right)$;

- $\quad \mathrm{P}_{\mathrm{k}+1}$ - ending point of edge $\left(\mathrm{P}_{\mathrm{k}}, \mathrm{P}_{\mathrm{k}+1}\right)$;

- distance $\left(P_{k}, P_{k+1}\right)$ - expressed in nautical miles from $\mathrm{P}_{\mathrm{k}}$ to chosen point $\mathrm{P}_{\mathrm{k}+1}$;

- $\mathrm{q}-\mathrm{a}$ total number of available weather forecasts $(\mathrm{i}=1$, $2, \ldots, \mathrm{q})$

- $t\left(P_{k}, P_{k+1}\right)$ - a table of travel times from $\mathrm{P}_{\mathrm{k}}$ to $\mathrm{P}_{\mathrm{k}+1}$ determined separately for each of q weather forecasts

- $\quad \alpha_{k, k+1}$ - true course from $\mathrm{P}_{\mathrm{k}}$ to $\mathrm{P}_{\mathrm{k}+1}$;

- $\quad c$-discomfort factor determined for moving from $\mathrm{P}_{\mathrm{k}}$ to $\mathrm{P}_{\mathrm{k}+1}$

To obtain sailing time from $\mathrm{P}_{\mathrm{k}}$ to $\mathrm{P}_{\mathrm{k}+1}$ we assume that the current weather forecast is valid for both points. Then, for such weather data, sailing conditions are determined based on the polar diagram presented in. Successive weather forecasts are taken into account for successive validity periods. An illustration of applying three successive weather forecasts is shown in Fig. 5. Three route parts for which successive weather forecasts, are taken into account are shown in white, red and blue background respectively. As a result, each edge is associated with a table of travel times, each of them determined depending on a particular weather forecast, which is valid for a specific period.

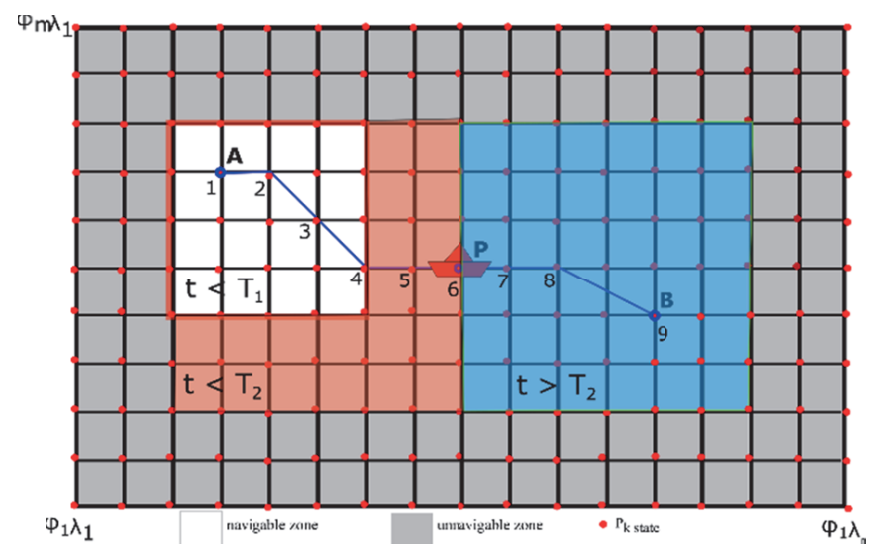

Fig. 5 Illustration of three different weather forecasts taken into account when determining a route

The total time of travelling a route is a sum of times determined for each straight segment and additional costs of changing direction. The latter is proportional to the size of course change and such a situation is shown in Fig. 6. 


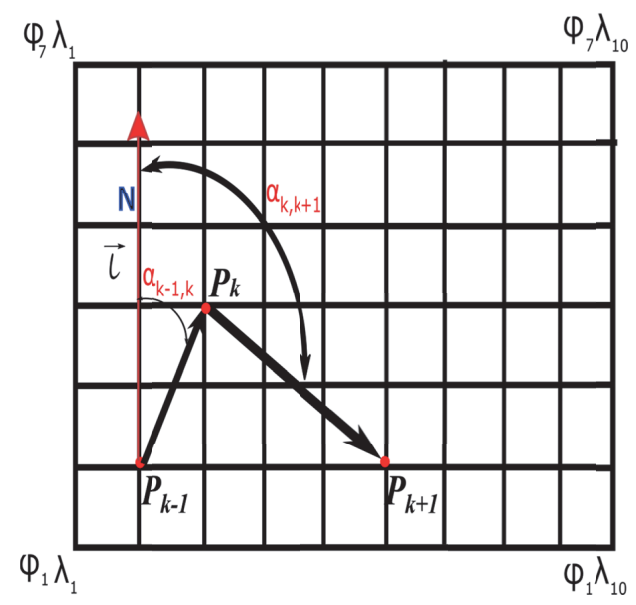

Fig. 6 A change of true course from $\alpha_{k-1, k}$ to $\alpha_{k, k+1}$ at point $P_{k}$

Once a dynamic graph is constructed, a customized version of a Dijkstra algorithm [16] is used to find the route, which minimizes the goal function (1). The algorithm that is used extends the classic Dijkstra algorithm by a number of elements, such as:

- dynamically computed weight of each edge (based on an exact time, when this edge is travelled), which takes into account sailing time and heel-dependant discomfort factor

- additional course alteration costs and penalties, which are added to the sum of weights

Since the sense of comfort is relative, the abovementioned discomfort factor is additionally dependant on a userconfigured parameters reflecting the user type and routing's purpose (regatta sailing, recreational sailing, passengers cruise etc.). The estimation of discomfort factor used here is inspired by research on cruise comfort published in 7 . The formula (8) from Section 3 has been calibrated to approximate discretised comfort estimation presented there.

\section{SIMULATION EXPERIMENTS AND THEIR RESULTS}

To investigate how the criterion of comfort and multiple weather forecasts affect the final route, we considered three variants of route optimisation. The first one, with discomfort factor set to 1 , totally ignores comfort criterion. The second one applies heel-dependant discomfort factor and course alteration-based penalties, which stimulate longer tacks. The third one additionally applies three successive weather forecasts to compare static routing with a dynamic one.

The proposed method weather routing has been implemented as SailingAssistance application, already mentioned in 29. The polar diagram data of a sailing vessel Conrad (Fig. 3) has been used throughout the experiments. The vessel's parameters are gathered in Table 1.
Tab.1 Parameters of Conrad 1200 RT

\begin{tabular}{|c|c|}
\hline Parameters & Value \\
\hline Sail area $\left[\mathrm{m}^{2}\right]$ & 80 \\
\hline Sail type & Bermuda rig \\
\hline Length $[\mathrm{m}]$ & 12.00 \\
\hline Beam $[\mathrm{m}]$ & 4.04 \\
\hline Draught $[\mathrm{m}]$ & 2 \\
\hline Free board $[\mathrm{m}]$ & 1.08 \\
\hline Waterplane $\left[\mathrm{m}^{2}\right]$ & 32.889 \\
\hline Lwl/Bwl $[-]$ & 3.161 \\
\hline Bwl/T [-] & 4.844 \\
\hline
\end{tabular}

Seven examples of determined routes are shown in Figures 7 to 13. Red arrows in each figure inform on wind direction from first weather forecast, one yellow arrow indicates the wind direction from the second weather forecast.

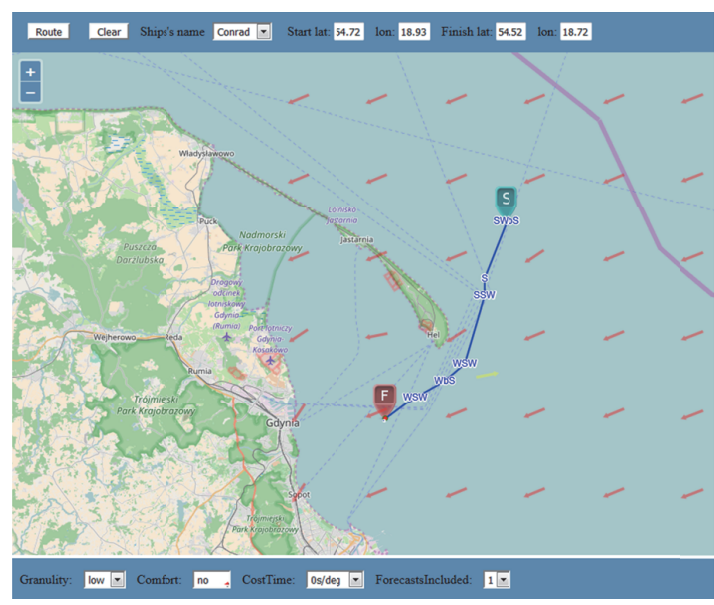

Fig. 7 Route 1, determined for the following settings: comfort criterion ignored costs of course changes set to 0 , only one weather forecast taken into account

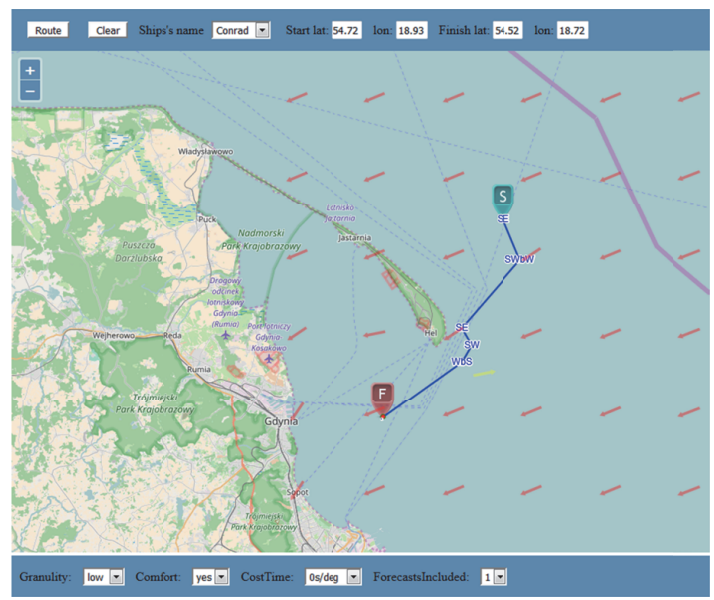

Fig. 8 Route 2, determined for the following settings: comfort criterion taken into account, costs of course changes set to 0 , only one weather forecast taken into account 


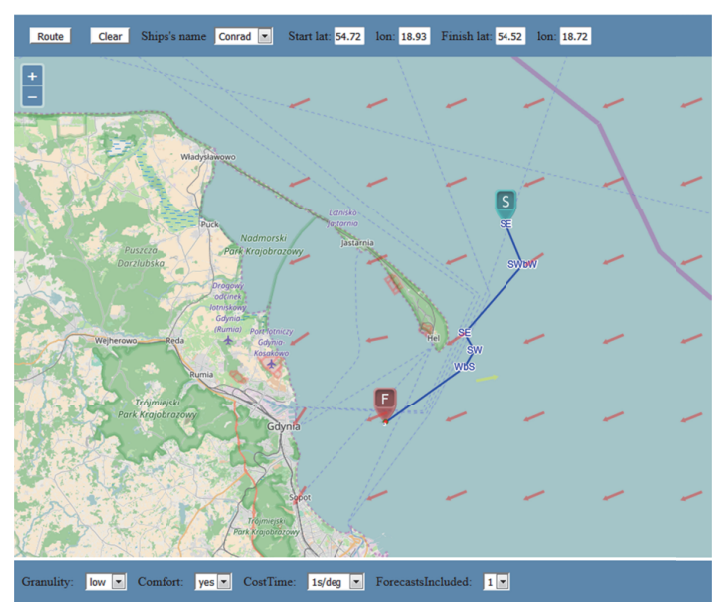

Fig. 9 Route 3, determined for the following settings: comfort criterion taken into account, costs of course changes set to 1 second per degree, only one weather forecast taken into account

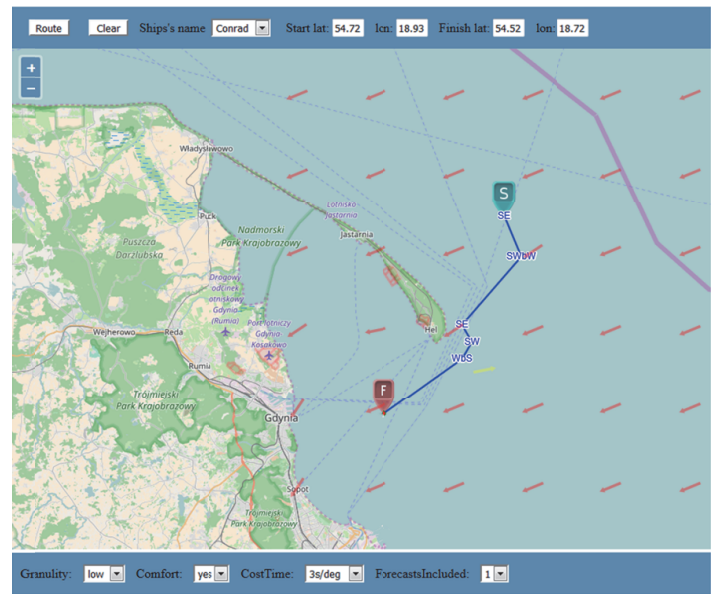

Fig. 10 Route 4, determined for the following settings: comfort criterion taken into account, costs of course changes set to 3 seconds per degree, only one weather forecast taken into account

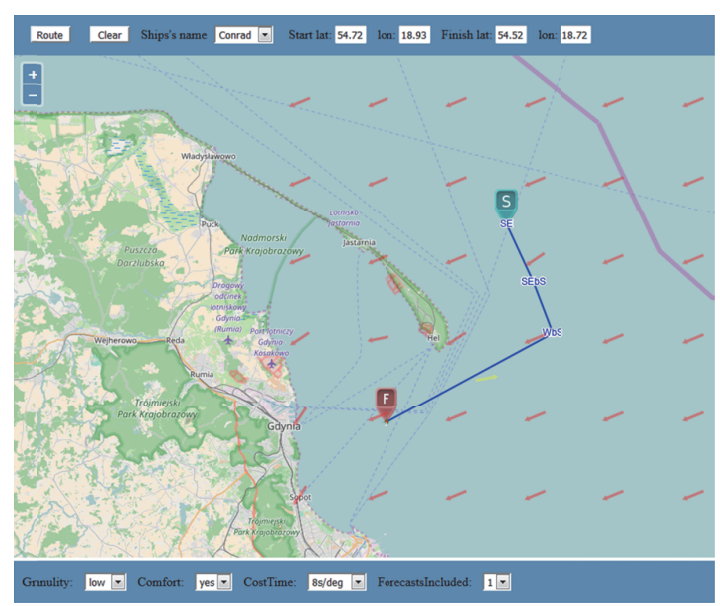

Fig. 11 Route 5, determined for the following settings: comfort criterion taken into account, costs of course changes set to $8 \mathrm{sec}$. per degree, only one weather forecast taken into account

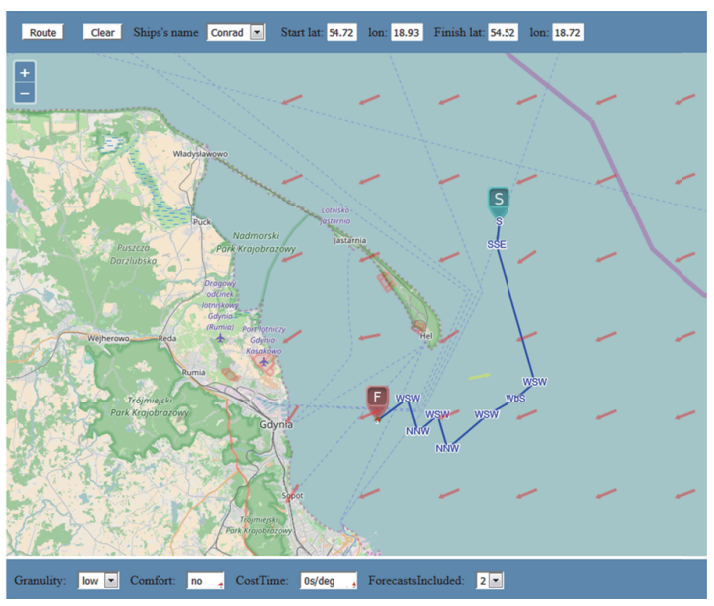

Fig. 12 Route 6, determined for the following settings: comfort criterion ignored, costs of course changes set to 0 , two successive weather forecasts taken into account

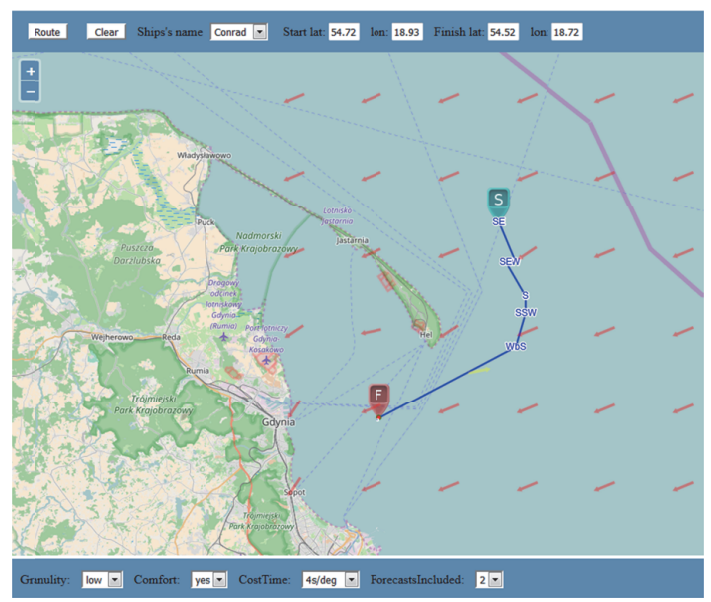

Fig. 13 Route 7, determined for the following settings: comfort criterion taken into account, costs of course changes set to 4 seconds per degree, two successive weather forecasts taken into account

Tab. 2 The example results

\begin{tabular}{|c|c|c|c|c|c|}
\hline $\begin{array}{c}\text { Route } \\
\text { number }\end{array}$ & $\begin{array}{c}\text { Comfort } \\
\text { criterion } \\
\text { taken into } \\
\text { account }\end{array}$ & $\begin{array}{c}\text { Cost of } \\
\text { a course } \\
\text { change } \\
\text { [sec/ } \\
\text { deg] }\end{array}$ & $\begin{array}{c}\text { Number } \\
\text { of } \\
\text { course } \\
\text { changes }\end{array}$ & $\begin{array}{c}\text { Number } \\
\text { of } \\
\text { weather } \\
\text { forecasts } \\
\text { taken } \\
\text { into } \\
\text { account }\end{array}$ & $\begin{array}{c}\text { Total voyage } \\
\text { time of } \\
\text { a route } \\
\text { (including } \\
\text { assumed cost } \\
\text { of course } \\
\text { changes) } \\
\text { [min] }\end{array}$ \\
\hline 1 & No & 0 & 5 & 1 & 121 \\
\hline 2 & Yes & 0 & 4 & 1 & 165 \\
\hline 3 & Yes & 1 & 4 & 1 & 168 \\
\hline 4 & Yes & 3 & 4 & 1 & 180 \\
\hline 5 & Yes & 8 & 2 & 1 & 231 \\
\hline 6 & No & 0 & 8 & 2 & 286 \\
\hline 7 & Yes & 4 & 4 & 2 & 304 \\
\hline & & & & & 1 \\
\hline
\end{tabular}




\section{CONCLUSIONS}

The obtained results allow us to draw the following conclusions:

- $\quad$ as expected, the number of course changes is decreasing with the increased cost of a course change resulting in the longer tacks for increased costs (Figures 8 to 11),

- taking into account comfort criterion results in longer routes and increased total voyage time (Figures 7 and 8)

- applying two successive weather forecasts instead of just one results in greatly different results, if the second forecast differs significantly from the first one (Figures 8 and 12)

The above observations show that the proposed method gives largely different results depending on the userconfigured values of the considered parameters. The proposed method is flexible, as it is able to take into account the particular user's needs like comfort. Finally, taking into account a number of successive weather forecasts, instead of assuming static weather, results in significantly different routes if the two forecasts differ drastically. This means that the routes determined for the static weather may in practice take more time than was predicted (total voyage time is not always reliable if static weather is assumed) or may even be unrealizable in some extreme cases. Further research on the method is planned and it is supposed to focus on applying a more accurate model of vessel's dynamics.

\section{ACKNOWLEDGMENTS}

The authors would like to thank Dr Bogusław Oleksiewicz for determining polar diagrams of sailing vessels used in this research.

\section{BIBLIOGRAPHY}

1. Arribas, F.L.P., A.L. Piniro: Seasickness prediction in passenger ships at the design stage, Ocean Eng. 34 (2007) 2086-2092.

2. Daniel, K., A. Nash, S. Koenig, A. Felner: Theta *: AnyAngle Path Planning on Grids, 39 (2010) 533-579.

3. Dębski, R.: An adaptive multi-spline refinement algorithm in simulation based sailboat trajectory optimization using onboard multi-core computer systems, Int. J. Appl. Math. Comput. Sci. 26 (2016) 351-365.

4. Dijkstra, E.W.: A Note on Two Probles in Connexion with Graphs, Numer. Math. 1 (1959) 269-271.

5. Disser, Y., M. Müller-Hannemann, M. Schnee: Multicriteria Shortest Paths in Time-Dependent Train Networks, in: Exp. Algorithms, Springer Berlin Heidelberg, Berlin, Heidelberg, 2008: pp. 347-361.
6. Geisberger, R.: Advanced Route Planning in Transportation Networks, (2011) 227.

7. Johnson, B.: Operator Guidance Based on Assessing the Wind - Heel Angle Relationship of Traditionally - Rigged Sailing Vessels, (n.d.).

8. Jurdziński, M.: Podstawy Nawigacji Morskiej, Wydawncitwo Akademii Morskiej w Gdyni, 2003.

9. Kerwin, J.: A velocity prediction program for ocean racing yachts revised to February 1978, M.I.T. Ocean Eng. Rep. Number 78-11, MIT, Cambridge, MA. (1978).

10. Lee, T., H. Chung, H. Myung: Multi-resolution path planning for marine surface vehicle considering environmental effects, Ocean. 2011 IEEE - Spain. (2011) $1-9$.

11. Lisowski, J.: Sensitivity of Computer Support Game Algorithms, Int. J. Appl. Math. Comput. Sci. 23 (2013) 439-446.

12. Lisowski, J.: ScienceDirect Computational intelligence methods of a safe ship control, Procedia - Procedia Comput. Sci. 35 (2014) 634-643.

13. Mannarini, G., G. Coppini, P. Oddo, N. Pinardi: A Prototype of Ship Routing Decision Support System for an Operational Oceanographic Service, TransNav, Int. J. Mar. Navig. Saf. Sea Transp. 7 (2013) 53-59.

14. Marchaj, C.: Teoria żeglowania. Aerodynamika żagla, IV, Alma-Press Sp. z o.o., Warszawa, 2016.

15. Neumann, T.: Method of Path Selection in the Graph Case Study, TransNav, Int. J. Mar. Navig. Saf. Sea Transp. 8 (2014) 557-562.

16. Philpott, A., A. Mason: Optimising yacht routes under uncertainty, Proc. 15th Chesap. Sail. Yacht Symp. Annapolis, MD. (2001).

17. Philpott, A.B., R.M. Sullivan, P.S. Jackson: Yacht velocity prediction using mathematical programming, Eur. J. Oper. Res. 67 (1993) 13-24

18. Ramalingam, G., T. Reps: On the computational complexity of dynamic graph problems, Theor. Comput. Sci. 158 (1996) 233-277.

19. Skriver, A.J.V., K.A. Andersen: A label correcting approach for solving bicriterion shortest-path problems, Comput. Oper. Res. 27 (2000) 507-524.

20. Specht, C., A. Weintrit, M. Specht, Y. Wo: A History of Maritime Radio- Navigation Positioning Systems used in 
Poland, (2017).

21. Stelzer, R.: Novel Algorithms and Experimental Demonstration, De Montfort University, Leicester, 2012.

22. Stelzer, R., K. Jafarmadar: The robotic sailing boat asv roboat as a maritime research platform, Proc. 22nd Int. HISWA Symp. Yacht Des. Yacht Constr. (2012).

23. Szlapczynska, J.: Multi-objective Weather Routing with Customised Criteria and Constraints, J. Navig. 68 (2015) 338-354.

24. Szlapczynski, R.: A New Method of Ship Routing on Raster Grids, with Turn Penalties and Collision Avoidance, J. Navig. 59 (2006) 27-42.

25. Weintrit, A., P. Kopacz: Computational Algorithms Implemented in Marine Navigation Electronic Systems, in: Springer, Berlin, Heidelberg, 2012: pp. 148-158.

26. Weintrit, A., R. Wawruch: Polish Approach to e-Navigation Concept, Communications. 1 (2007) 327-335.

27. Wilcox, B.H., T. Litwin, J. Biesiadecki, J. Matthews, M. Heverly, J. Morrison, J. Townsend, N. Ahmad, A. Sirota, B. Cooper: ATHLETE: A Cargo Handling and Manipulation Robot for the Moon, J. F. Robot. 24 (2007) 421-434.

28. Życzkowski, M.: Sailing Vessel Routing Considering Safety Zone and Penalty Time for Altering Course, TransNav, Int. J. Mar. Navig. Saf. Sea Transp. 11 (2017) 49-54.

29. Życzkowski, M.: METHOD OF ROUTING SHIPS SAILING IN DEDICATED ENVIRONMENT, Annu. Navig. 24 (2017) 147-159.

\section{CONTACT WITH THE AUTHOR}

Rafł Szłapczyński

Marcin Życzkowski

Gdańsk University of Technology 11/12 Narutowicza St. 80 - 233 Gdańsk

Poland 